\title{
Physicochemical and tribological properties of gemini-type halogen-free dicationic ionic liquids
}

\author{
Qiangliang YU ${ }^{1,2}$, Chaoyang ZHANG ${ }^{1}$, Rui DONG ${ }^{1,3}$, Yijun SHI ${ }^{4}$, Yurong WANG ${ }^{1,3}$, Yanyan BAI ${ }^{1,3}$, Jiaying ZHANG ${ }^{1,3}$, \\ Meirong CAI ${ }^{1, *}$, Feng ZHOU ${ }^{1, *}$, Weimin LIU ${ }^{1}$ \\ ${ }^{1}$ State Key Laboratory of Solid Lubrication, Lanzhou Institute of Chemical Physics, Chinese Academy of Sciences, Lanzhou 730000, China \\ ${ }^{2}$ Lubricating Oil Key Laboratory of Petro China, Lanzhou Lubricating Oil Research \& Development Institute of Petro China, Lanzhou \\ 730060, China \\ ${ }^{3}$ Center of Materials Science and Optoelectronics Engineering, University of Chinese Academy of Sciences, Beijing 100049, China \\ ${ }^{4}$ Division of Machine Elements, Luleå University of Technology, Luleå 97187, Sweden \\ Received: 21 January 2019/Revised: 31 July 2019 / Accepted: 03 December 2019 \\ (C) The author(s) 2019.
}

\begin{abstract}
A series of new halogen-free dicationic ionic liquids (ILs) with different alkyl chain lengths were prepared, and the relationship between the alkyl chain length, physicochemical and tribological properties of ILs, and their role as neat lubricant for steel-steel friction pairs, was investigated. Evaluation of stability during hydrolysis and copper strip corrosion test results show that synthetic ILs are stable and not corrosive to metal contacts, due to the halogen-free anions. The friction and wear test results indicate that ILs with long alkyl chains have excellent friction-reducing and anti-wear properties, especially at high temperatures. Based on the surface three-dimensional (3D) profiles, electrical contact resistance, scanning electron microscopy (SEM), energy dispersive X-ray spectroscopy (EDS), and the X-ray photoelectron spectrometry (XPS) analysis of the worn surfaces of steel discs, we can conclude that the efficiency of ILs is due to the formation of high quality tribofilms that consist of both tribochemical reaction and ordered absorption films.
\end{abstract}

Keywords: halogen-free; dicationic ionic liquids (ILs); lubricant; tribofilm

\section{Introduction}

Friction and wear result in energy wastage and shorten the service life of mechanical components [1]. The reasonable use of liquid lubricants is one of the most effective ways to prevent friction and wear. In general, liquid lubricants are mainly divided into two categories - natural and synthetic lubricants. Natural lubricants include some animal fat, vegetable oils, and mineral oils [2]. Synthetic lubricants commonly contain synthetic hydrocarbon, synthetic ester, and perfluoropolyethers (PFPEs), and are widely used in special conditions, such as applications that require high temperature stability, low saturated vapor pressures, excellent extreme pressure, and oxidation stability [3].

The discovery of ionic liquids (ILs) as high performance synthetic lubricants was initiated in 2001 [4]. The study of ILs as lubricant has since received increasing attention [5-8]. ILs have been explored as lubricants for various frictional materials, due to their excellent dipolar structure and physical properties like extremely low volatility, nonflammability, high thermal stability, low melting point, and good thermal conductivity; the latter allowing for rapid frictional heat dissipation [9-14]. Currently, a large number of studies in the tribological field are mainly focused on halogen-containing mono-cation ILs based on anions

* Corresponding authors: Meirong CAI, E-mail: caimr@licp.cas.cn; Feng ZHOU, E-mail: zhouf@licp.cas.cn 
such as $\left[\mathrm{BF}_{4}\right]^{-},\left[\mathrm{PF}_{6}\right]^{-},\left[\mathrm{CF}_{3} \mathrm{SO}_{3}\right]^{-}$, and $\left[\mathrm{NTf}_{2}\right]^{-}[15-17]$. In 2006, dicationic ionic liquid lubricants were first reported by Ref. [18]. In this study, polyethylene glycol functionalized dicationic ILs with alkyl or polyfluoroalkyl substitutents were prepared. It is noteworthy that these ILs also exhibit excellent tribological characteristics even at $300{ }^{\circ} \mathrm{C}$. A new series of dicationic symmetrical and asymmetrical ILs consisting of tetraalkylphosphonium and alkylimidazolium were synthesized, which have very high decomposition temperature of approximately $450{ }^{\circ} \mathrm{C}$ and good tribological properties [19]. Pagano et al. [20] synthesized and investigated twelve dicationic ILs as potential lubricant, which were synthesized from oligoethylene glycols linking two cationic moieties based on either N-methylimidazolium or $\mathrm{N}$-methylpyrrolidinium at the extremities. As anions, chloride, bis(trifluoromethanesulfonyl)imide [ $\left[\mathrm{NTf}_{2}\right]^{-}$, methanesulfonate and butanesulfonate were chosen. Mahrova et al. [21] synthesized a series of bi-cationic pyridine-type ILs, and systematically studied their tribological properties as lubricant and additive. This series of ILs uses $\left[\mathrm{NTf}_{2}\right]^{-}$as an anion and exhibits excellent friction-reduction and anti-wear properties. However, ILs containing $\left[\mathrm{BF}_{4}\right]^{-},\left[\mathrm{PF}_{6}\right]^{-},\left[\mathrm{CF}_{3} \mathrm{SO}_{3}\right]^{-}$, and $\left[\mathrm{NTf}_{2}\right]^{-}$usually undergo hydrolysis when used as lubricants. They can cause metal corrosion and can pollute the environment [22]. Hence, replacement of ILs with halogen-free high-efficiency IL lubricants is becoming increasingly popular in modern ILs tribology [23-28]. Gusain et al. [29] synthesized and evaluated a series of bis(imidazolium)- and bis(ammonium)-di[bis(salicylato)borate] ILs with variable alkyl chain and cyclic ring structures as potential lubricant additives. These dicationic ILs as additives of PEG200 showed noncorrosive properties, which were attributed to the of corrosion driven elements, such as halogens, in these ILs.

In this study, we designed a new type of halogenfree dicationic IL, based on the gemini-type molecular structure. The cation part is a double quaternary ammonium structure, and the anion is a phosphate ester. We adopted the N/P synergistic lubrication concept. The constructed ILs are excellent lubricants and have excellent thermal stability.

\section{Experimental}

\subsection{Chemicals}

The reagents, including $\mathrm{N}, \mathrm{N}, \mathrm{N}^{\prime}, \mathrm{N}^{\prime}$-tetramethylethylenediamine, bromotetradecane, bromohexadecane, bromooctadecyl, bis(2-ethylhexyl) hydrogen phosphate, and sodium hydroxide were obtained from SigmaAldrich. Di-isooctyl phosphate sodium was prepared according to previously reported methods [30]. The molecular structures of 1,2-bis-N,N-dimethyl-Ntetradecylammonium bis (2-ethylhexyl) phosphate (NP-14-2-14), 1,2-bis-N,N-dimethyl-N-cetylammonium bis (2-ethylhexyl) phosphate (NP-16-2-16), 1,2-bis-N,Ndimethyl-N-octadecylammonium bis (2-ethylhexyl) phosphate (NP-18-2-18), are shown in Fig. 1. The method of these three gemini-type ILs has been reported in detail by our previously reported Ref. [31]. The structures and purities of dicationic ILs (NP-142-14, NP-16-2-16 and NP-18-2-18) were finely confirmed by ${ }^{1} \mathrm{H}$ NMR, ${ }^{13} \mathrm{C}$ NMR, ${ }^{31} \mathrm{P} \mathrm{NMR}$, and MS spectroscopic data. Detailed data are presented in the Electronic Supplementary Material (ESM).

\subsection{Thermal stability and viscosity analysis}

Thermal stability and viscosity-temperature performance are the most basic characteristics of good lubricants. Therefore, thermogravimetric analysis (TGA)
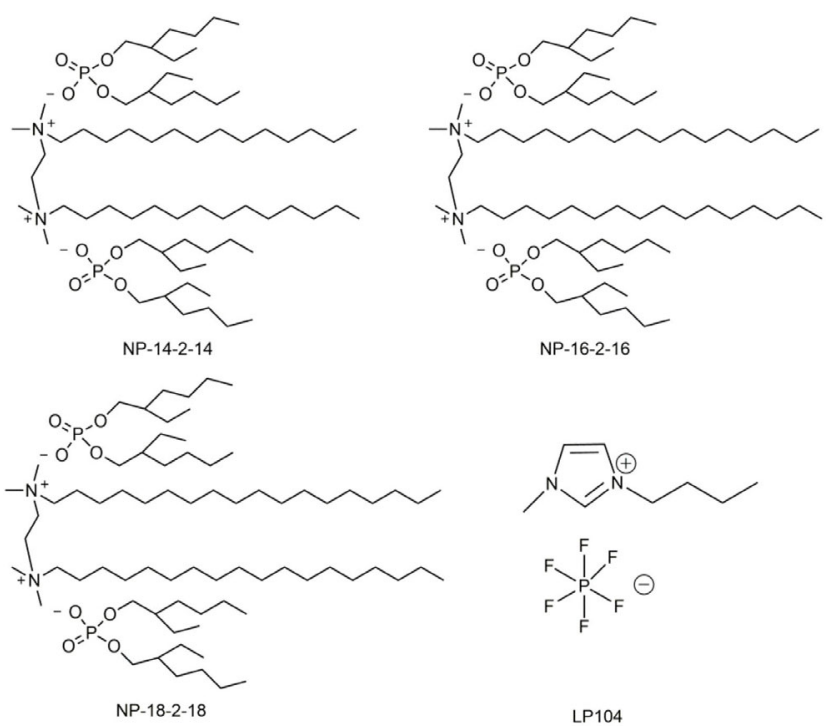

Fig. 1 Molecular structures of selected dicationic ILs and 1-butyl-3-methylimidazolium hexafluorophosphate (L-P104) as a comparative synthetic lubricant. 
was conducted on a Netzsch STA 449 F3 synchronous thermal analyzer system, in a nitrogen atmosphere at a temperature of $10{ }^{\circ} \mathrm{C} / \mathrm{min}$, to test the thermal stability of PAO 10, L-P104, NP-14-2-14, NP-16-2-16, and NP-18-2-18. Kinematic viscosities of all samples were measured at temperatures of 40 and $100{ }^{\circ} \mathrm{C}$ using a SYP1003-III kinematic viscosity tester.

\subsection{Copper strip corrosion test}

The copper strip corrosion test was performed according to the National standard GB-T5096-1985(91) [32]. Prior to the test, copper strips with a certain specification $(12.0 \mathrm{~mm} \times 12.0 \mathrm{~mm} \times 3.0 \mathrm{~mm})$ were polished to brightness and completely cleaned with ethanol. The copper strips were then immersed into the test lubricants (PAO 10, L-P104, and NP-18-2-18). The samples were heated at $100{ }^{\circ} \mathrm{C}$ for $24 \mathrm{~h}$. After the experiment, the copper strips were taken out and washed carefully with ethanol, and then the corrosion level was gauged using a standard corrosion plate for comparison.

\subsection{Hydrolysis stability}

The hydrolytic stability experiments of NP-18-2-18 refer to previously reported methods [33]. NP-18-218 was mixed with water in equal quantity. The solutions were then heated at $80{ }^{\circ} \mathrm{C}$ for $24 \mathrm{~h}$. The $\mathrm{pH}$ of the solutions was checked at an interval of $30 \mathrm{~min}$ to determine the hydrolysis levels of NP-18-2-18. In comparison, the hydrolysis stability of PAO 10 and L-P104 was measured simultaneously using the same method.

\subsection{Tribology test and surface analysis}

The tribological properties of NP-14-2-14, NP-16-2-16, and NP-18-2-18 for the steel-steel friction pair were evaluated using a reciprocating ball-on-disk sliding test on an Optimol SRV-V. Table 1 shows the test parameters based on previously reported methods [34, 35], at environmental humidity of $30 \%-50 \%$, using an upper slide ball (model specifications: AISI 52100 bearing steel; diameter: $10 \mathrm{~mm}$; hardness: 59-63 HRC; mean roughness: $100 \mathrm{~nm}$ ) and lower stationary steel disk (ø $24 \mathrm{~mm} \times 7.9 \mathrm{~mm}$, hardness: 59-63 HRC). A Bruker NPFLEX non-contact surface mapping profiler was used to determine the profile of the wear scar
Table 1 Test parameters of the SRV test.

\begin{tabular}{cc}
\hline Parameter & Value \\
\hline Friction pairs & Steel/steel \\
Load $(\mathrm{N})$ & 300 \\
Frequency $(\mathrm{Hz})$ & 25 \\
Temperature $\left({ }^{\circ} \mathrm{C}\right)$ & $25 / 100$ \\
Amplitude $(\mathrm{mm})$ & 1 \\
Duration $(\mathrm{min})$ & 30 \\
Voltage $(\mathrm{V})$ & 20 \\
\hline
\end{tabular}

and the corresponding wear volume.

An FEI Quanta FEG 250 SEM with EDS (type: Oxford IE250) was used to observe the morphology and composition of the surface of wear scars. XPS (type: PHI-5702) was used to further observe the binding energy of elements distributed on the surface of the wear scar, to better understand the lubrication mechanism.

\section{Results and discussion}

\subsection{Physicochemical properties}

\subsubsection{Thermal analysis}

The thermal stability of all lubricants was tested, and the results are presented in Fig. 2 and Table 2. It can be observed that the thermal decomposition temperatures $\left(T_{\mathrm{d}}\right)$ of PAO $10\left(\sim 280.5^{\circ} \mathrm{C}\right)$ and L-P104 $\left(\sim 400^{\circ} \mathrm{C}\right)$ are very high, whereas the $T_{\mathrm{d}}$ values of NP-14-2-14 $\left(\sim 212.4{ }^{\circ} \mathrm{C}\right), \mathrm{NP}-16-2-16\left(\sim 233.1{ }^{\circ} \mathrm{C}\right)$, and NP-18-2-18 $\left(\sim 238.1{ }^{\circ} \mathrm{C}\right)$ are relatively low. The thermal decomposition temperatures of dicationic IL were also found

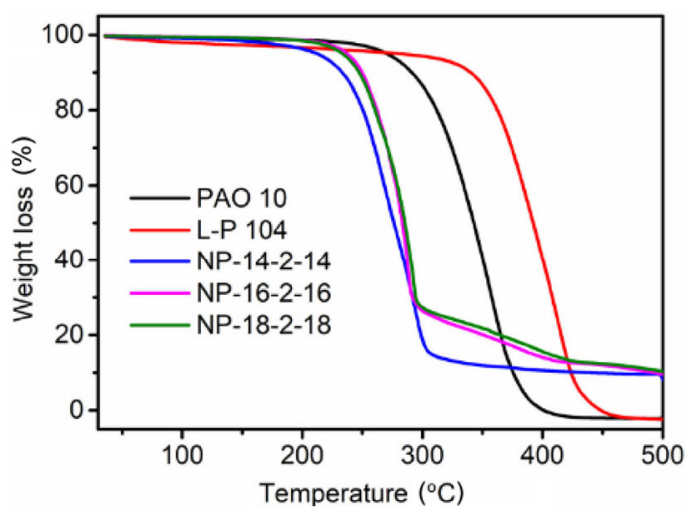

Fig. 2 TGA curves of PAO 10, L-P104, NP-14-2-14, NP-16-2-16, and NP-18-2-18. 
Table 2 Kinematic viscosities $(\mathrm{KVs})$ at $40{ }^{\circ} \mathrm{C}\left(\mathrm{KV}_{40}\right), 100{ }^{\circ} \mathrm{C}\left(\mathrm{KV}_{100}\right)$, and VIs of dicationic ILs and the reference samples.

\begin{tabular}{|c|c|c|c|c|c|c|c|}
\hline \multirow{2}{*}{ Lubricant } & \multicolumn{2}{|c|}{ KVs } & \multirow{2}{*}{ VI } & \multirow{2}{*}{$T_{\mathrm{d}}\left({ }^{\circ} \mathrm{C}\right)$} & \multicolumn{3}{|c|}{ TG temperature $\left({ }^{\circ} \mathrm{C}\right)$ per weight loss } \\
\hline & $\mathrm{KV}_{40}\left(\mathrm{~mm}^{2} / \mathrm{s}\right)$ & $\mathrm{KV}_{100}\left(\mathrm{~mm}^{2} / \mathrm{s}\right)$ & & & $10 \%$ & $20 \%$ & $50 \%$ \\
\hline PAO 10 & 63.75 & 9.64 & 133.10 & 280.47 & 290.40 & 310.40 & 341.90 \\
\hline L-P104 & 83.80 & 10.97 & 117.60 & 380.97 & 383.53 & 404.73 & 443.23 \\
\hline NP-14-2-14 & $2,856.10$ & 108.51 & 107.10 & 212.44 & 233.10 & 250.30 & 276.30 \\
\hline NP-16-2-16 & $3,365.10$ & 125.89 & 113.40 & 233.07 & 249.70 & 261.90 & 283.30 \\
\hline NP-18-2-18 & $3,529.90$ & 156.85 & 137.30 & 238.77 & 247.20 & 260.40 & 285.50 \\
\hline
\end{tabular}

to increase slightly with increasing length of the alkyl chain, which can be attributed to an increase in Van der Waals interactions among the IL's molecules [18]. Table 2 shows the corresponding $T_{\mathrm{d}}$ for different mass losses. $T_{\mathrm{d}}$ shows an obvious gradual increase with a loss of weight. For example, $T_{\mathrm{d}}$ of PAO 10 indicates a $50 \%$ weight loss at $\sim 340{ }^{\circ} \mathrm{C}$, and the $T_{\mathrm{d}}$ of L-P104 indicates the same at $440{ }^{\circ} \mathrm{C}$. There is $50 \%$ weight loss for all dicationic ILs at a temperature exceeding $250{ }^{\circ} \mathrm{C}$. This suggests that synthetic ILs have appropriate thermal stability and can meet the lubrication requirements both at room temperature (RT) and high temperature (HT).

\subsubsection{Viscosity}

KVs and viscosity indexes (VIs) are also summarized in Table 2. The viscosities of dicationic ILs are obviously higher than those of PAO 10 and L-P104 at RT and $100{ }^{\circ} \mathrm{C}$. The viscosity index of NP-14-2-14, NP-16-2-16, and L-P104 is approximately 110; PAO 10 and NP-18-2-18 have the highest viscosity indexes at approximately 130 . The KVs and VIs of the dicationic IL lubricants gradually increase with the increase in alkyl chain length. This is attributed to the increase in Van der Waals interactions between the IL's molecules [36].

\subsubsection{Hydrolysis stability}

Compared to conventional halogen-containing ILs, halogen-free ILs demonstrate excellent hydrolytic stability [15]. In this study, the hydrolysis stability of halogen-free dicationic ILs was first evaluated by using a hydrolysis test according to Ref. [22]. Figure 3 shows no significant $\mathrm{pH}$ change during the test, which indicates that PAO 10 and halogen-free dicationic ILs are hydrolysis stable. Under the same test conditions,

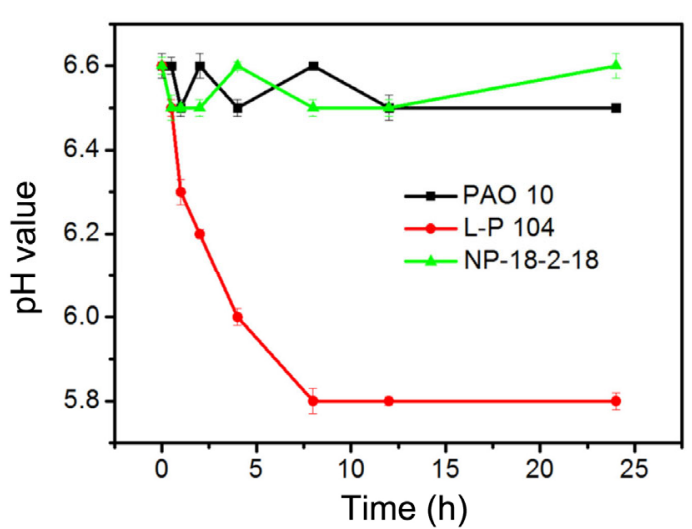

Fig. $3 \mathrm{pH}$ value change curves of the samples.

L-P104 showed rapid hydrolysis with a drop in $\mathrm{pH}$ value at the very beginning of the test.

\subsubsection{Copper strip corrosion test}

Traditional halogen-containing ILs can attack substrates due to their hydrolysis, to produce acidic materials $[37,38]$. The purpose of designing halogen-free dicationic ILs is to improve the lubricating properties of ILs and reduce their corrosion performance. Therefore, the copper strip corrosion test was developed to confirm anti-corrosion properties, using PAO 10 and L-P104 as references. The photographs of the polished copper strips (Fig. 4(a)) after soaking in PAO 10 (Fig. 4(b)), L-P104 (Fig. 4(c)), and NP-18-2-18 (Fig. 4(d)), respectively, are shown in Fig. 4. Compared to blank copper, it is evident that the surface of the copper sheet immersed in L-P104 is found to be corroded. This surface looks tarnished and is covered with a large amount of corrosion products (Fig. 4(c)), while only a small amount of darkening was observed on the surfaces of the copper strips soaked in PAO 10 (Fig. 4(b)) and NP-18-2-18 (Fig. 4(d)). According to the standard corrosion plate, it can be concluded that 


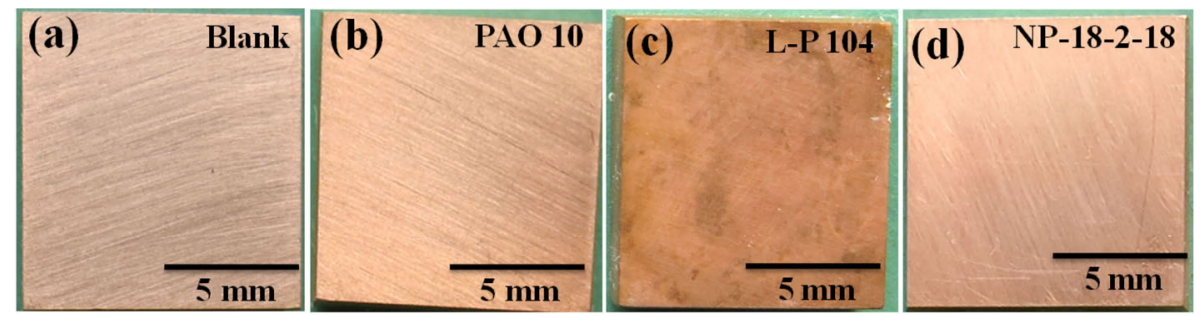

Fig. 4 Photographs of copper strips (a) before and (b-d) after the corrosion test: (b) PAO 10, (c) L-P104, and (d) NP-18-2-18.

the corrosion grade for L-P104 was 2a, whereas those for PAO 10 and NP-18-2-18 were $1 \mathrm{a}$.

\subsection{Analysis of friction and wear properties as lubricants for steel-steel friction pairs}

The friction coefficient (COF) and wear volume of NP-14-2-14, NP-16-2-16, and NP-18-2-18 were first tested at RT (Fig. 5). Figure 5(a) shows that the COF of PAO 10 is very high at 0.6 and then gradually reduces to an equilibrium of 0.2 , which is attributed to the non-polar property of PAO molecules in that they do not easily adsorb on the metal interface. Furthermore, there are no special elements such as $\mathrm{N}$ and $\mathrm{P}$ in the molecule that can cause frictional chemical reactions; thus, PAO 10 has a very high wear volume of up to $1.2 \times 10^{-3} \mathrm{~mm}^{3}$ (Fig. 5(b)). The COFs of NP-14-2-14, NP-16-2-16, and NP-18-2-18 are low and stable. A significant decrease in COF is observed in the entire process, with an increase in alkyl chain length. This law is consistent with the experimental results of wear volume (Fig. 5(b)), suggesting that the alkyl chain length of ILs has an important effect on the stability of the boundary lubricant film, considering the lubrication interval. The average COF for all synthetic ILs is less than 0.1 , which is a good numerical range for a good boundary lubrication area according to Ref. [39]. Compared to PAO 10, NP-14-2-14, NP-16-2-16, and NP-18-2-18, L-P104 exhibited a very low and smooth COF and relatively low wear volume. It is easy to understand that L-P104 is more suitable as a lubricant for steel-steel system at RT, mainly because of the contribution of active element content (high F, P, and $\mathrm{N}$ element percentage) in molecules and viscosity.

Under $100{ }^{\circ} \mathrm{C}$, the COF of PAO 10 has equal shares at RT (Fig. 6(a)), but indicates a greater wear volume of approximately $2.0 \times 10^{-3} \mathrm{~mm}^{3}$ during the sliding process (Fig. 6(b)). The final COF of NP-18-2-18 is less than that of L-P104. The anti-wear properties of NP-16-2-16 and NP-18-2-18 are also superior to those of L-P104 (Fig. 6(b)). As expected, the reduction of the COF and wear volume of NP-16-2-16 and NP-18-2-18 is evident, indicating that the friction reduction and anti-wear performance of dicationic ILs can be enhanced by introducing long alkyl chains at HT. Furthermore, a suitably high lubricant viscosity is beneficial for forming a thicker lubricating film, since long alkyl chains are superior for stronger hydrophobic interactions at HT. The formation of a stable lubricating film is thus caused by a
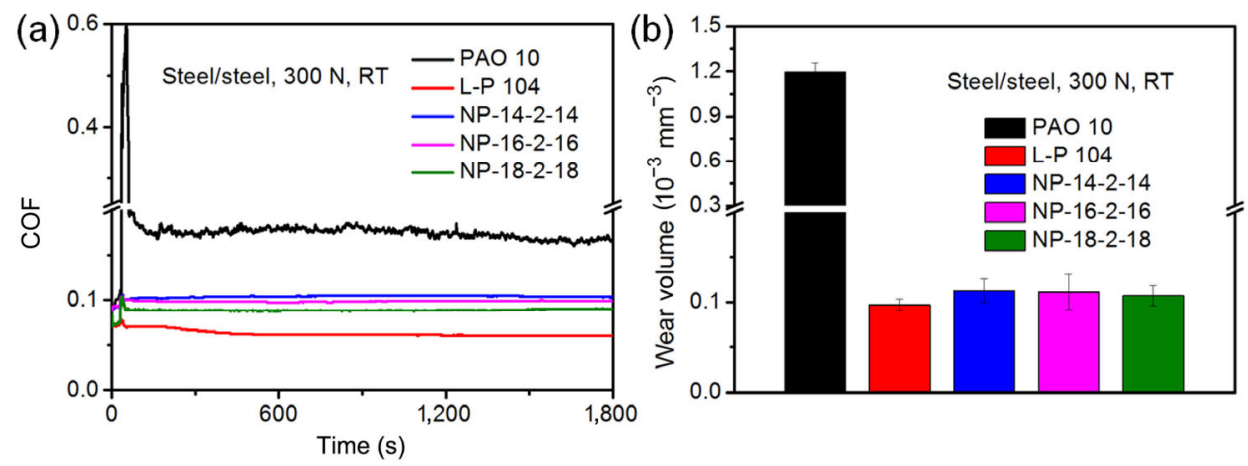

Fig. 5 Evolution of (a) COF/time and (b) wear volumes of PAO 10, L-P104, NP-14-2-14, NP-16-2-16, and NP-18-2-18 for steel-steel contact at $300 \mathrm{~N}, 25 \mathrm{~Hz}$, and RT. 

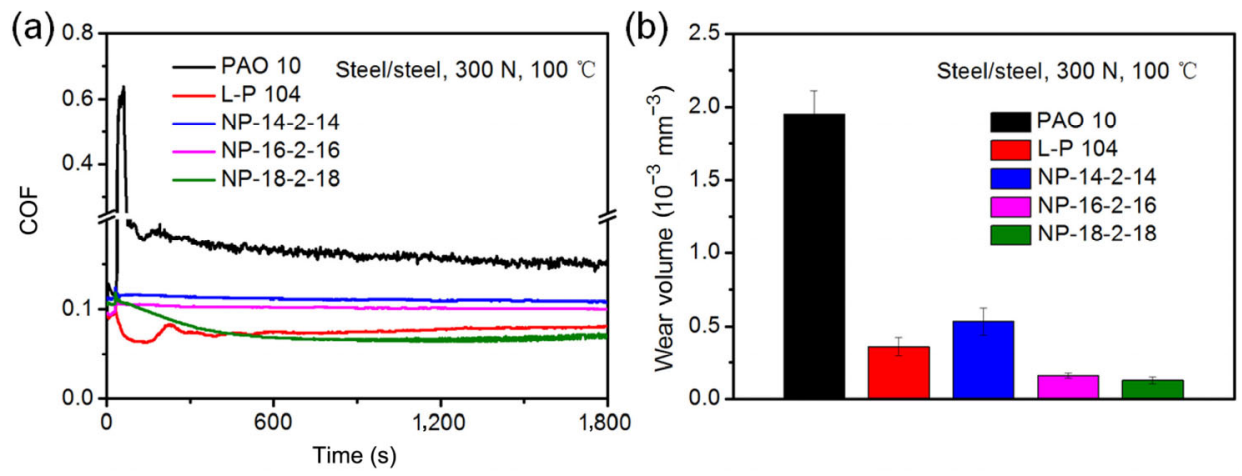

Fig. 6 Evolution of (a) COF/time and (b) wear volumes of PAO 10, L-P104, NP-14-2-14, NP-16-2-16, and NP-18-2-18 for steel-steel contact at $300 \mathrm{~N}, 25 \mathrm{~Hz}$, and $100{ }^{\circ} \mathrm{C}$.

strengthened interaction and enhanced lubrication in NP-16-2-16 and NP-18-2-18.

\subsection{Surface analysis of wear spot}

\subsubsection{Surface profile analysis}

The three-dimensional (3D) optical microscopic images of the wear spots at RT and $100{ }^{\circ} \mathrm{C}$, are exhibited in Figs. 7 and 8 , respectively. The results are consistent with the wear volume analysis. The wear scar diameter (WSD) and wear scar depth (WSD') of PAO 10 are $2.3 \mathrm{~mm}$ and $-6 \mu \mathrm{m}$, respectively (Fig. 7 ), and there are obvious protrusions around the wear scar. In comparison, the WSD and WSD' values of other lubricants were significantly reduced. For example, for a lubricated surface of L-P104 (Fig. 7(b)), the WSD was approximately $1.2 \mathrm{~mm}$, and the WSD' was approximately $-0.5 \mu \mathrm{m}$. The same phenomenon was observed for other dicationic ILs lubricants (Figs. 7(c)-7(e)). However, if we look closely at Figs. 7(c)-7(e), the reduction in WSD and WSD' is obvious. These results also prove that as the alkyl chain increases, the lubricating properties of the ions also increase.

At $100{ }^{\circ} \mathrm{C}$, the $3 \mathrm{D}$ morphology of the wear surface is similar to that at RT. The obvious difference is that the wear spot of the PAO 10 lubricant has a larger WSD and a deeper WSD' (Fig. 8(a)). For surfaces lubricated by L-P104 (Fig. 8(b)) and NP-14-2-14
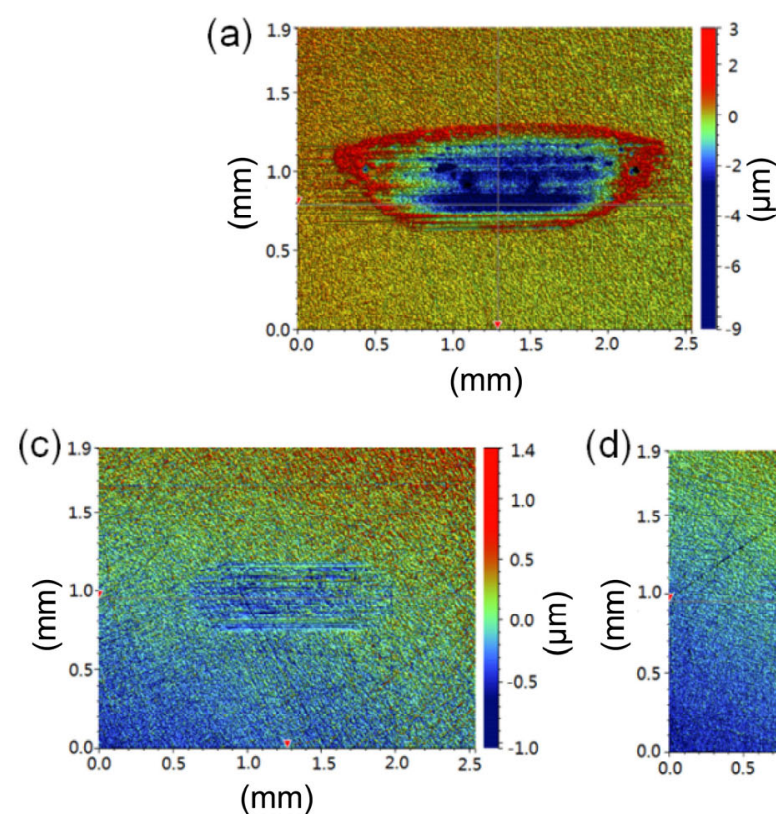
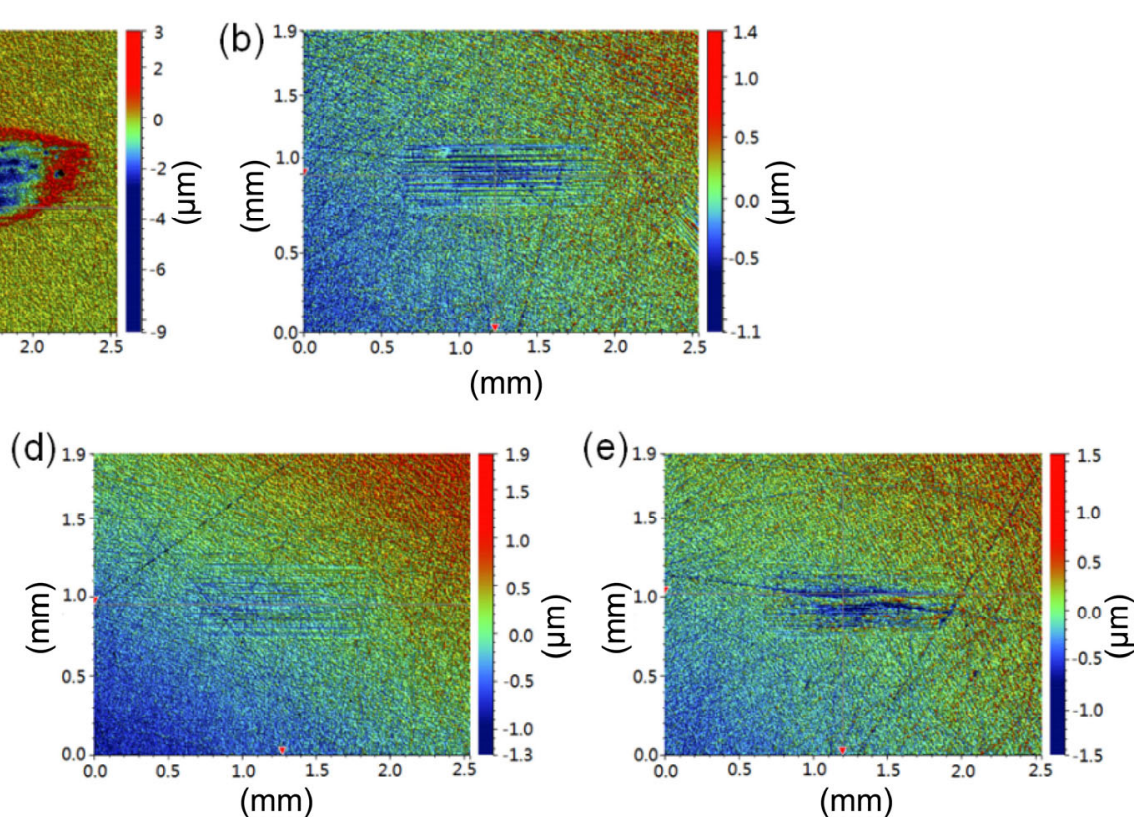

Fig. 7 3D optical microscopic images of wear tracks (steel-steel friction pairs) corresponding to (a) PAO 10, (b) L-P104, (c) NP-14-2-14, (d) NP-16-2-16, and (e) NP-18-2-18 at RT. 
(a)
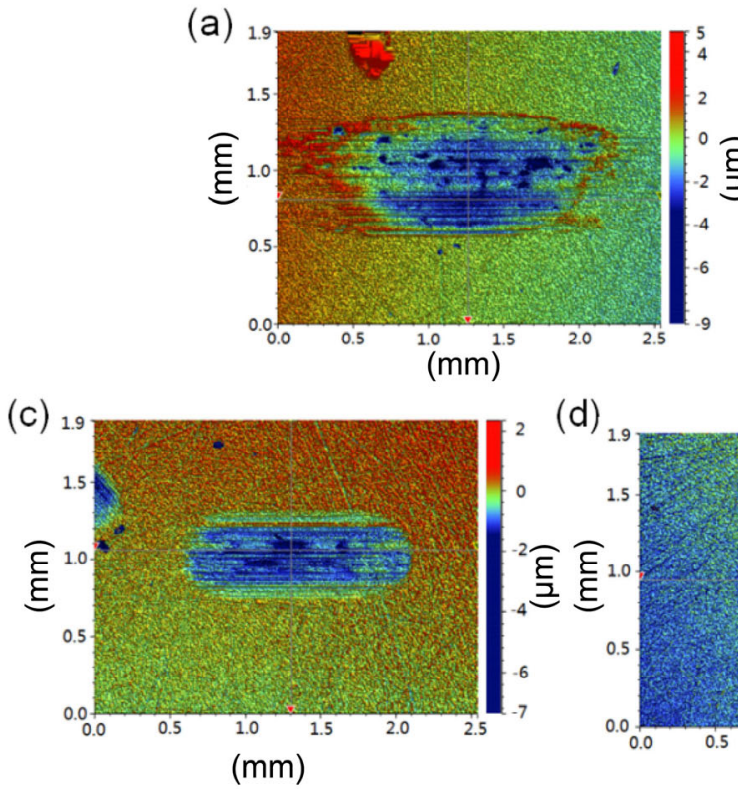

(b)

(d)

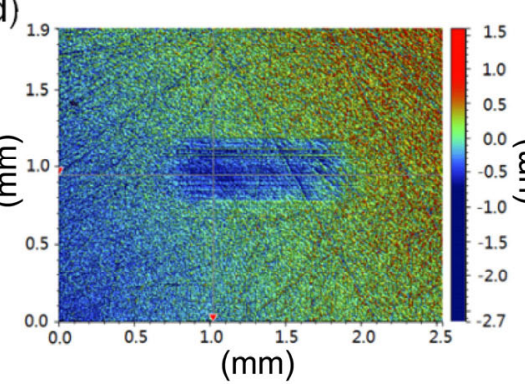

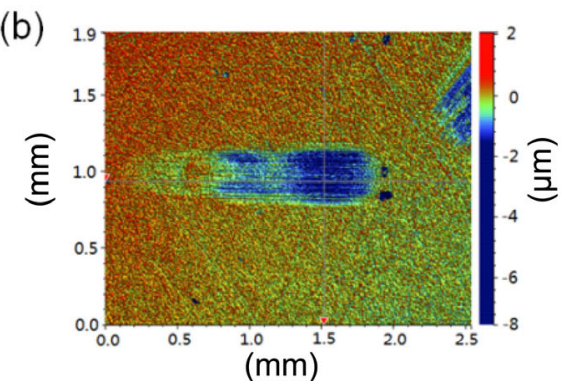

(e)

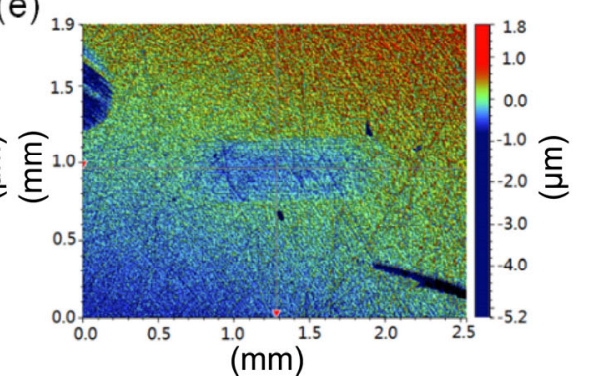

Fig. 8 3D optical microscopic images of wear tracks (steel-steel friction pairs) corresponding to (a) PAO 10, (b) L-P104, (c) NP-14-2-14, (d) NP-16-2-16, and (e) NP-18-2-18 at $100{ }^{\circ} \mathrm{C}$.

(Fig. 8(c)), the wear was significantly heavier than that at RT. However, for other lubricants, the increase in WSD and WSD' is small (Fig. 8(b)-8(e)) at $100{ }^{\circ} \mathrm{C}$ compared to at RT. It is worth noting that as the alkyl chain length increases, WSD and WSD' decrease significantly, which means that high-viscosity ILs are more advantageous for reducing friction and wear at HTs.

\subsubsection{SEM analysis}

The SEM images show worn surfaces of the lubricated steel at RT and $100{ }^{\circ} \mathrm{C}$ (Figs. S1 and S2 (ESM)). Using ILs as lubricants at RT significantly reduces wear. For example, from Figs. S1(a)-S1(e) (ESM), it can be seen that the wear spot diameter is significantly reduced, and the surfaces of wear become better. However, SEM topographies magnified to 1,000 times indicate that obvious differences exist between various lubricants. For example, steel surfaces lubricated with PAO 10 (Fig. S1(a1) (ESM)) and L-P104 (Fig. S1(a2) $(\mathrm{ESM})$ ) have obvious adhesive wear, as observed under an SEM at a magnification of 3,000 times. Deep pits appear on the surface that was lubricated with PAO 10 (Fig. S1(a2) (ESM)), suggesting a failure of lubrication. The lubricated surface of L-P104 (Fig. S1(a2) (ESM)), with a large black area indicates metal surface corrosion caused by anion hydrolysis. When observed clearly, the worn surfaces lubricated by NP-14-2-14,
NP-16-2-16, and NP-18-2-18 have neither obvious scratches nor corrosion, implying excellent anti-wear and anti-corrosion properties of IL NP-14-2-14, NP16-2-16, and NP-18-2-18.

\subsection{Simple analysis of lubrication mechanism}

\subsubsection{Electrical contact resistance (ECR) analysis}

Using ECR, measurements can offer a visualization of the change in interface resistance and the formation of an interface tribofilm [40, 41]. During friction, ECR changes were gauged from the lubrication interface at RT (Fig. 9(a)) or at HT (Fig. 9(b)), and the results are consistent with those of the wear volume analysis. Combined with Figs. 5, 6, and 9, it can be easily concluded that a reduction in friction is related to the formation of tribofilm on worn surfaces, which is caused by changes in the ECR values. For example, the ECR of PAO 10 is very low at about $0.1 \Omega$ regardless of whether it is at $\mathrm{RT}$ or $100{ }^{\circ} \mathrm{C}$, and this corresponds to the highest COF. In contrast, the ECR values of dicationic IL lubricants changed from 0.1 to higher ECR values and a lower COF was observed. More importantly, the ECR increases significantly with an increase in alkyl chain length for dicationic ILs. This change is more pronounced at HT, suggesting that ILs are more likely to form an insulating lubricating 

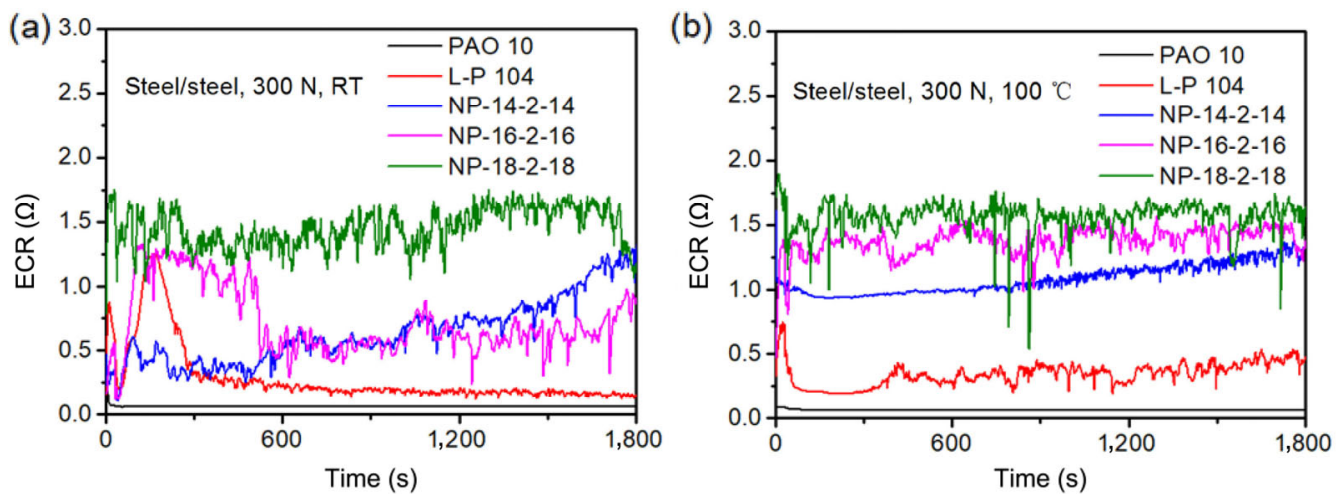

Fig. 9 ECR of PAO 10, L-P104, NP-14-2-14, NP-16-2-16, and NP-18-2-18 as lubricants for steel-steel at (a) RT and (b) $100{ }^{\circ} \mathrm{C}$ with a load of $300 \mathrm{~N}$ and frequency of $25 \mathrm{~Hz}$.

protective film at the interface through adsorption or tribochemical reaction during the rubbing process, thus providing better anti-friction and anti-wear properties. In contrast, although L-P104 exhibits low friction at both RT and HT, its ECR is not as high as that of the dicationic ILs. We suspect that the change in ECR is closely related to the conductivity of the lubricant. To further explain this phenomenon, the conductivity of L-P104, NP-14-2-14, NP-16-2-16, and NP-18-2-18 were tested, and shown in Table S1 of the supporting information. As can be seen from Table S1 (ESM), the conductivities of L-P104, NP-14-2-14, NP-16-2-16, and NP-18-2-18 were 1,451, 7.31, 6.98, and $6.33 \mu \mathrm{S} / \mathrm{cm}$, respectively. Compared with L-P104, dicationic ILs have a very low conductivity, which results in a high contact resistance during the rubbing process. In addition, compared with L-P104, dicationic ILs have a longer alkyl chain, and form a denser and thicker lubricating film [42], and thus their ECR values are larger.

\subsubsection{EDS analysis}

The friction test at RT showed the chemical composition of wear scars, which was confirmed by EDS. Figures S3(a)-S3(e) (ESM) represent elements in the wear spot after lubrication by different lubricants, respectively. In Figs. S3(a) and S3(a1)-S3(e1) (ESM), elements $\mathrm{C}, \mathrm{O}$, and $\mathrm{Fe}$ appear on the surface of the wear scar and on the outside of the wear scar, suggesting that these lubricants do not react with the metal during friction. Figures S3(a)-S3(e) (ESM) show some special elements, such as $\mathrm{F}, \mathrm{P}$, and $\mathrm{N}$ that appear on the center of the wear scar, indicating that NP-14-2-14,
NP-16-2-16, and NP-18-2-18 are consistent with L-P104, which undergo a complex tribochemical reaction with the steel, forming a stable boundary lubrication film. This reduces friction and enhances anti-wear properties [43].

With friction at HT, the element distribution on the surface of the wear scar is exactly the same as the element distribution after friction at RT.

\subsubsection{XPS analysis}

To gain further information about the lubricating effect of the halogen-free dicationic ILs, XPS analysis of the boundary film on worn steel surfaces following friction was conducted for elements such as $\mathrm{Fe}, \mathrm{O}, \mathrm{P}$, and N. Figure 10 shows the XPS curve of the worn surface lubricated with NP-16-2-16 and L-P104, at RT and $100{ }^{\circ} \mathrm{C}$. Figure 10 indicates that the XPS spectra of surfaces lubricated with NP-16-2-16 and L-P104 are quite similar, both at RT and HT. In the case of the Fe 2p XPS spectrum (Fig. 10(a)), Fe 2p peaks appear at approximately 710.8 and $724.5 \mathrm{eV}$, associated with the binding energy (BE) of 530.2 and $531.8 \mathrm{eV}$ in the $\mathrm{O}$ 1s spectrum (Fig. 10(b)). They can be identified as $\mathrm{Fe}_{2} \mathrm{O}_{3}, \mathrm{Fe}_{3} \mathrm{O}_{4}$, and/or $\mathrm{Fe}(\mathrm{OH}) \mathrm{O}$ [44]. As shown in Fig. 10(c), the BE of $\mathrm{P} 2 \mathrm{p}$ at about $133.8 \mathrm{eV}$ might correspond to compounds that contain $\mathrm{PO}_{4}{ }^{3-}$ [45-47], and the $\mathrm{P} 2 \mathrm{p}$ at $134.80 \mathrm{eV}$ is attributed to alkyl phosphate. In addition, the peak of $\mathrm{P} 2 \mathrm{p}$ at $133.8 \mathrm{eV}$ is assigned to $\mathrm{FePO}_{4}$, which coincides with the $\mathrm{Fe} 2 \mathrm{p}$ peak of $712.80 \mathrm{eV}$. This indicates that NP-16-2-16 decomposes and reacts with the exposed metal surface to produce a protective film composed of phosphates and/or polyphosphates, which improves the tribological 
(a)

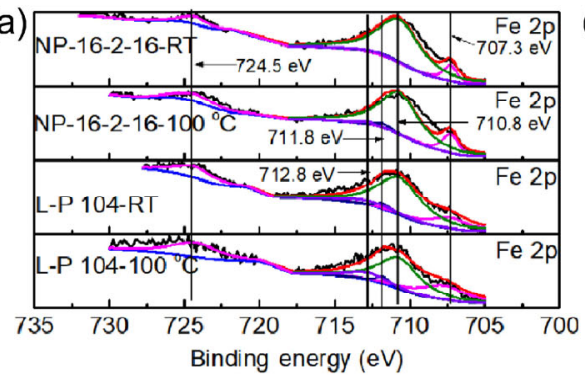

(b)

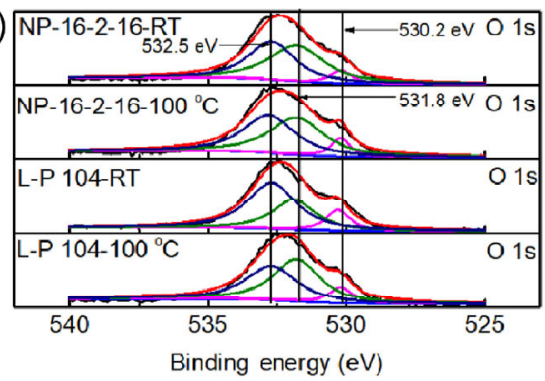

(c)

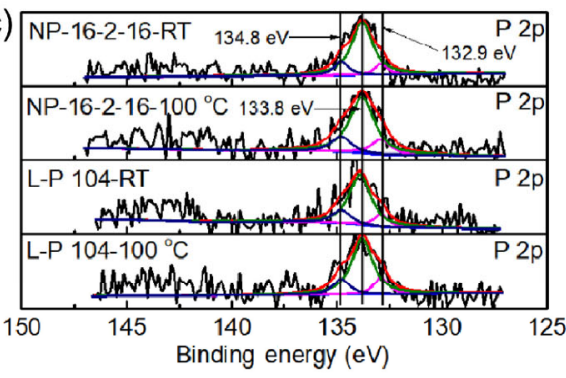

(d) NP-16-2-16-RT

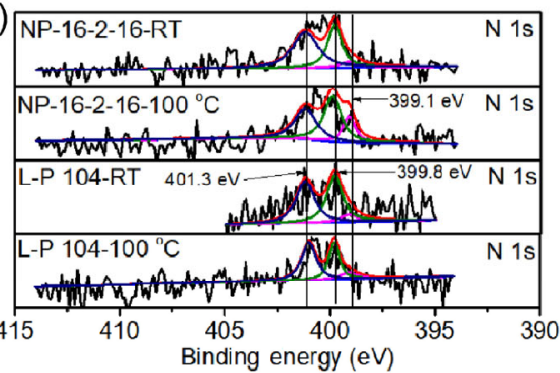

(e)

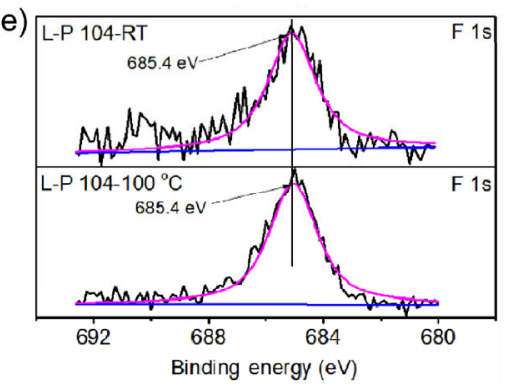

Fig. 10 XPS spectra of (a) Fe 2p, (b) O 1s, (c) P 2p, (d) N 1s, and (e) F 1s lubricated by NP-16-2-16 and L-P104 at RT and HT $($ load $=300 \mathrm{~N}$; stroke $=1 \mathrm{~mm}$; frequency $=25 \mathrm{~Hz}$; duration $=30 \mathrm{~min})$.

properties [47]. From Fig. 10(d), the $\mathrm{N}$ 1s peak of $401.30 \mathrm{eV}$ indicates a complex phosphorus oxide species, namely $\left(\mathrm{NH}_{4}\right)_{2} \mathrm{HPO}_{4}$, and the $\mathrm{O} 1$ s peak of $531.50 \mathrm{eV}$ also indicates this compound [48]. The $\mathrm{N} 1 \mathrm{~s}$ peak of $399.80 \mathrm{eV}$ may correspond to $\mathrm{C}-\mathrm{N}$ bonding and nitrogen being transformed into to organic amines $[49,50]$. The $\mathrm{N} 1$ s peak at $399.10 \mathrm{eV}$ is attributed to phosphinic amide, which coincides with the $\mathrm{P} 2 \mathrm{p}$ peak of $132.90 \mathrm{eV}$. The above results together indicate that a new nitride and phosphorus compound such as $\mathrm{FePO}_{4}$ and complex organic nitrogen compounds were generated on the worn surfaces during the sliding process [47]. For a surface lubricated by L-P104, as shown in Fig. 10(e), the XPS peaks of F 1s, P 2p, and Fe $2 p$ appear at $685.4,133.8$, and $711.8 \mathrm{eV}$, respectively, which are assigned to $\mathrm{FeF}_{2}$ and $\mathrm{FePO}_{4}$ [46].

\section{Conclusions}

A series of halogen-free dicationic ILs equipped with long alkyl chains were synthesized and evaluated as lubricants for a steel-steel friction pair at RT and HT, with the aim of studying the relationship between the alkyl-chain length and the tribological properties of double cationic ILs. Increasing the alkyl chain length of the cation has proven to be effective in improving ILs in terms of thermal stability, corrosion resistance, and tribological performance, especially at HT. Based on the results of COF, SEM, ECR, EDS, and XPS, the excellent lubrication of ILs comes from the boundary lubricating protection film containing phosphorus and nitrogen that forms on the sliding steel surfaces, which achieves superior tribological properties by a phosphorus-nitrogen synergy.

\section{Acknowledgements}

The authors acknowledge financial support from the National Key Research and Development Program of China (2018YFB0703802), the National Natural Science Foundation of China (Grant Nos. 51705504, 21972153, and 51675512), the China Postdoctoral Science Foundation Funded Project (2019M653798), the Youth Innovation Promotion Association of CAS (2018454), the pre-research project in the manned space field (040101), and the Gansu Province Science and Technology Plan (18ZD2WA011).

Electronic Supplementary Material Supplementary material is available in the online version of this article at https://doi.org/10.1007/s40544-019-0348-5.

Open Access This article is licensed under a Creative Commons Attribution 4.0 International License, which 
permits use, sharing, adaptation, distribution and reproduction in any medium or format, as long as you give appropriate credit to the original author(s) and the source, provide a link to the Creative Commons licence, and indicate if changes were made.

The images or other third party material in this article are included in the article's Creative Commons licence, unless indicated otherwise in a credit line to the material. If material is not included in the article's Creative Commons licence and your intended use is not permitted by statutory regulation or exceeds the permitted use, you will need to obtain permission directly from the copyright holder.

To view a copy of this licence, visit http://creativecommons.org/licenses/by/4.0/.

\section{References}

[1] Huang G W, Yu Q L, Ma Z F, Cai M R, Zhou F, Liu W M. Oil-soluble ionic liquids as antiwear and extreme pressure additives in poly- $\alpha$-olefin for steel/steel contacts. Friction 7(1): 18-31 (2019)

[2] Jiang C, Li W M, Nian J Y, Lou W J, Wang X B. Tribological evaluation of environmentally friendly ionic liquids derived from renewable biomaterials. Friction 6(2): 208-218 (2018)

[3] Ray S, Rao P V C, Choudary N V. Poly- $\alpha$-olefin-based synthetic lubricants: A short review on various synthetic routes. Lubr Sci 24(1): 23-44 (2012)

[4] Ye C, Liu W, Chen Y, Yu L. Room-temperature ionic liquids: A novel versatile lubricant. Chem Commun 21: 2244-2245 (2001)

[5] Zhou F, Liang Y M, Liu W M. Ionic liquid lubricants: Designed chemistry for engineering applications. Chem Soc Rev 38(9): 2590-2599 (2009)

[6] Bermúdez M D, Jiménez A E, Sanes J, Carrión F J. Ionic liquids as advanced lubricant fluids. Molecules 14(8): 2888-2908 (2009)

[7] Minami I. Ionic liquids in tribology. Molecules 14(6): 2286-2305 (2009)

[8] Cai M R, Yu Q L, Zhou F, Liu W M. Physicochemistry aspects on frictional interfaces. Friction 5(4): 361-382 (2017)

[9] Jiménez A E, Bermúdez M D. Ionic liquids as lubricants of titanium-steel contact. Tribol Lett 33(2): 111-126 (2009)

[10] Lu Q M, Wang H Z, Ye C F, Liu W M, Xue Q J. Room temperature ionic liquid 1-ethyl-3-hexylimidazolium-bis (trifluoromethylsulfonyl)-imide as lubricant for steel-steel contact. Tribol Int 37(7): 547-552 (2004)

[11] Yao M H, Liang Y M, Xia Y Q, Zhou F, Liu X Q. Hightemperature tribological properties of 2-substituted imidazolium ionic liquids for $\mathrm{Si}_{3} \mathrm{~N}_{4}$-steel contacts. Tribol Lett 32(2): 73-79 (2008)

[12] Liu X Q, Zhou F, Liang Y M, Liu W M. Tribological performance of phosphonium based ionic liquids for an aluminum-on-steel system and opinions on lubrication mechanism. Wear 261(10): 1174-1179 (2006)

[13] Zhu M, Yan J, Mo Y F, Bai M W. Effect of the anion on the tribological properties of ionic liquid nano-films on surfacemodified silicon wafers. Tribol Lett 29(3): 177-183(2008)

[14] Li D M, Cai M R, Feng D P, Zhou F, Liu W M. Excellent lubrication performance and superior corrosion resistance of vinyl functionalized ionic liquid lubricants at elevated temperature. Tribol Int 44(10): 1111-1117 (2011)

[15] Song Z H, Liang Y M, Fan M J, Zhou F, Liu W M. Ionic liquids from amino acids: Fully green fluid lubricants for various surface contacts. RSC Adv 4(37): 19396-19402 (2014)

[16] González R, Ramos D, Blanco D, Fernández-González A, Viesca J L, Hadfield M, Battez A H. Tribological performance of tributylmethylammonium bis (trifluoromethylsulfonyl) amide as neat lubricant and as an additive in a polar oil. Friction 7(3): 282-288 (2019)

[17] Minami I, Kita M, Kubo T, Nanao H, Mori S. The tribological properties of ionic liquids composed of trifluorotris (pentafluoroethyl) phosphate as a hydrophobic anion. Tribol Lett 30(3): 215-223 (2008)

[18] Jin C M, Ye C F, Phillips B S, Zabinski J S, Liu X Q, Liu W M, Shreeve J M. Polyethylene glycol functionalized dicationic ionic liquids with alkyl or polyfluoroalkyl substituents as high temperature lubricants. J Mater Chem 16(16): 1529-1535 (2006)

[19] Yu G Q, Yan S Q, Zhou F, Liu X Q, Liu W M, Liang Y M. Synthesis of dicationic symmetrical and asymmetrical ionic liquids and their tribological properties as ultrathin films. Tribol Lett 25(3): 197-205 (2007)

[20] Pagano F, Gabler C, Zare P, Mahrova M, Dörr N, Bayón R, Fernandez X, Binder W H, Hernaiz M, Tojo E, Igartua A. Dicationic ionic liquids as lubricants. P I Mech Eng J-J Eng 226(11): 952-964 (2012)

[21] Mahrova M, Pagano F, Pejakovic V, Valea A, Kalin M, Igartua A, Tojo E. Pyridinium based dicationic ionic liquids as base lubricants or lubricant additives. Tribol Int $\mathbf{8 2}$ : 245-254 (2015)

[22] Dong R, Wen P, Zhang S, Zhang C Y, Sun W J, Fan M J, Yang D S, Zhou F, Liu W M. The synthesis and tribological properties of dicarboxylic acid ionic liquids. Tribol Int 114: 132-140 (2017)

[23] Fukaya Y, Iizuka Y, Sekikawa K, Ohno H. Bio ionic liquids: Room temperature ionic liquids composed wholly of biomaterials. Green Chem 9(11): 1155-157 (2007) 
[24] Totolin V, Minami I, Gabler C, Dörr N. Halogen-free borate ionic liquids as novel lubricants for tribological applications. Tribol Int 67: 191-198 (2013)

[25] Fan M J, Song Z H, Liang Y M, Zhou F Liu W M. Laxative inspired ionic liquid lubricants with good detergency and no corrosion. ACS Appl Mater Interfaces 6(5): 3233-3241 (2014)

[26] Fan M J, Yang D S, Wang X L, Liu W M, Fu H Z. DOSS-Based QAILs: As both neat lubricants and lubricant additives with excellent tribological properties and good detergency. Ind Eng Chem Res 53(46): 17952-17960 (2014)

[27] Abbott A P, Ahmed E I, Harris R C, Ryder K S. Evaluating water miscible deep eutectic solvents (DESs) and ionic liquids as potential lubricants. Green Chem, 16(9): 4156-4161 (2014)

[28] Gusain R, Gupta P, Saran S, Khatri O P. Halogen-free bis (imidazolium)/bis (ammonium)-di[bis(salicylato)borate] ionic liquids as energy-efficient and environmentally friendly lubricant additives. ACS Appl Mater Interfaces 6(17): 15318-15328 (2014)

[29] Gusain R, Singh R, Sivakumar K L N, Khatri O P. Halogen-free imidazolium/ammonium-bis (salicylato) borate ionic liquids as high performance lubricant additives. RSC Adv 4(3): 1293-1301 (2014)

[30] Jiang D, Hu L T, Feng D P Crown-type ionic liquids as lubricants for steel-on-steel system. Tribol Lett 41(2): 417-424 (2011)

[31] Yu Q L, Zhang C Y, Dong R, Shi Y J, Wang Y R, Bai Y Y, Zhang J Y, Cai M R, Zhou F. Novel N-, P-containing oil-soluble ionic liquids with excellent tribological and anticorrosion performance. Tribol Int 132: 118-129 (2019)

[32] Huang G W, Yu Q L, Cai M R, Zhou F, Liu W M. Investigation of the lubricity and antiwear behavior of guanidinium ionic liquids at high temperature. Tribol Int 114: 65-76 (2017)

[33] Song Z H, Yu Q L, Cai M R, Huang G W, Yao M H, Li D M, Liang Y M, Fan M J, Zhou F. Green ionic liquid lubricants prepared from anti-inflammatory drug. Tribol Lett 60(3): 38 (2015)

[34] Yu Q L, Ma Z F, Cai M R, Zhou F, Liu W M. Tribological behavior of laser textured steel impregnated with supramolecular gel lubricant. P I Mech Eng J-J Eng 231(9): 1151-1159 (2017)

[35] Yu Q L, Li D M, Cai M R, Zhou F, Liu W M. Supramolecular gel lubricants based on amino acid derivative gelators. Tribol Lett 61(2): 16 (2016)

[36] Yao M H, Fan M J, Liang Y M, Zhou F, Xia Y Q. Imidazolium hexafluorophosphate ionic liquids as high temperature lubricants for steel-steel contacts. Wear $\mathbf{2 6 8}$ (1-2): 67-71 (2010)

[37] Liu X, Zhou F, Liang Y, Liu W. Benzotriazole as the additive for ionic liquid lubricant: One pathway towards actual application of ionic liquids. Tribol Lett 23(3): 191-196 (2006)

[38] Cai M R, Liang Y M, Zhou F, Liu W M. Tribological properties of novel imidazolium ionic liquids bearing benzotriazole group as the antiwear/anticorrosion additive in poly (ethylene glycol) and polyurea grease for steel/steel contacts. ACS Appl Mater Interfaces 3(12): 4580-4592 (2011)

[39] Qu J, Luo H M, Chi M F, Ma C, Blau P J, Dai S, Viola M B. Comparison of an oil-miscible ionic liquid and ZDDP as a lubricant anti-wear additive. Tribol Int 71: 88-97 (2014)

[40] Viesca J L, García A, Battez A H, González R, Monge R, Fernández-González A, Hadfield M. FAP ${ }^{-}$anion ionic liquids used in the lubrication of a steel-steel contact. Tribol Lett 52(3): 431-437 (2013)

[41] Viesca J L, Battez A H, González R, Reddyhoff T, Pérez A T, Spikes H A. Assessing boundary film formation of lubricant additivised with 1-hexyl-3-methylimidazolium tetrafluoroborate using ECR as qualitative indicator. Wear 269(1-2): 112-117 (2010)

[42] Xiao H P, Guo D, Liu S H, Pan G S, Lu X C. Film thickness of ionic liquids under high contact pressures as a function of alkyl chain length. Tribol Lett 41(2): 471-477 (2011)

[43] Papay A G. Antiwear and extreme-pressure additives in lubricants. Lubr Sci 10(3): 209-224 (1998)

[44] Yu Q L, Wang Y R, Huang G W, Ma Z F, Shi Y J, Cai M R, Zhou F, Liu W M. Task-specific oil-miscible ionic liquids lubricate steel/light metal alloy: A tribochemistry study. $A d v$ Mater Interfaces 19(5): 1800791 (2018)

[45] Wang Y R, Yu Q L, Ma Z F, Huang G W, Cai M R, Zhou F, Liu W M. Significant enhancement of anti-friction capability of cationic surfactant by phosphonate functionality as additive in water. Tribol Int 112: 86-93 (2017)

[46] Wang H Z, Lu Q M, Ye C F, Liu W M, Cui Z J. Friction and wear behaviors of ionic liquid of alkylimidazolium hexafluorophosphates as lubricants for steel/steel contact. Wear 256(1-2): 44-48 (2004)

[47] Zhu L L, Zhao G Q, Wang X B. Investigation on three oilmiscible ionic liquids as antiwear additives for polyol esters at elevated temperature. Tribol Int 109: 336-345 (2017)

[48] Qiao D, Wang H Z, Feng D P. Benzimidazolyl phosphates as anti-wear additives in poly (ethylene glycol) for steel/steel contacts. Lubr Sci 26(1): 1-11 (2014)

[49] Viesca J L, Mallada M T, Blanco D, Fernández-González A, Espina-Casado J, González R, Battez A H. Lubrication performance of an ammonium cation-based ionic liquid used as an additive in a polar oil. Tribol Int 116: 422-430 (2017)

[50] Cao Z F, Xia Y Q, Chen C. Fabrication of novel ionic liquids-doped polyaniline as lubricant additive for anti-corrosion and tribological properties. Tribol Int 120: 446-454 (2018) 


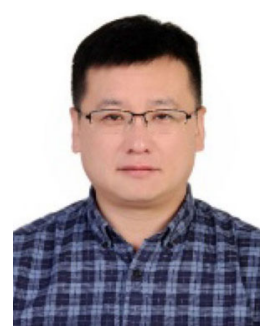

Qiangliang YU. He got his Ph.D. in 2016 at Lanzhou Institute of Chemical Physics, Chinese Academy of Sciences, China. He is an associate professor at the State Key Lab of

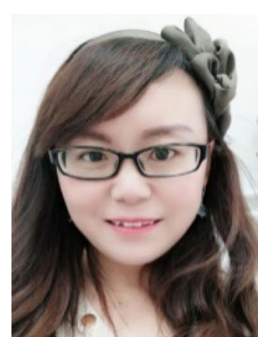

Meirong CAI. She got her Ph.D. in 2012 at Lanzhou Institute of Chemical Physics, Chinese Academy of Sciences, China. She is an associate professor at the State Key

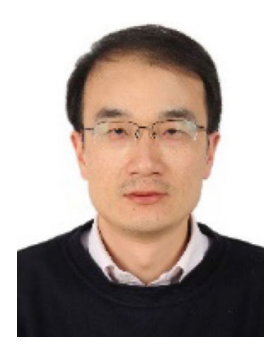

Feng ZHOU. He is a full professor in Lanzhou Institute of Chemical Physics, Chinese Academy of Sciences, China, and director of State Key Laboratory of Solid Lubrication, China. He gained his Ph.D. in 2004 and spent three years (2005-2008) in the Department of Chemistry, University of Cambridge as a research associate. He has published more than 300 journal papers that received more
Solid Lubrication in Lanzhou Institute of Chemical Physics, Chinese Academy of Sciences, China. His research focuses on the synthesis of task-specific ionic liquids lubricants, organic corrosion inhibitors, and the functional anti-corrosion coating.

Lab of Solid Lubrication in Lanzhou Institute of Chemical Physics, Chinese Academy of Sciences, China. She has authored or co-authored 70 journal papers. Her research interests are tribochemistry, ionic liquids lubricants, and supramolecular gel lubricants.

than 17,000 citations and has the high-index 72 . His research interests include the bioninspired tribology, biomimic surfaces/interfaces of soft matters, dragreduction and antibiofouling, and functional coatings. He has gained a number of awards including "Outstanding Youth Award" of International Society of Bionic Engineering, 2013, and one National Award for Natural Sciences (the second class). He serves as an editorial board member of Tribology International, Journal of Fiber Bioengineering and Informatics, etc. 